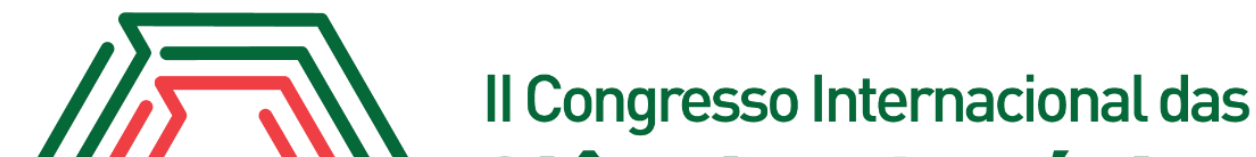 Ciências Agrárias COINTER - PDVAgro 2017
}

\section{DESEMPENHO DE CORDEIROS FILHOS DE MATRIZES SUPLEMENTADAS EM PASTO DIFERIDO}

\author{
Apresentação: Pôster
}

Nathália Rafaela Fidelis Campos ${ }^{1}$; Adalla Thainna de Andrade Silva ${ }^{2}$; Roldão Teixeira de Carvalho Netto ${ }^{3}$; Ana Beatriz Graciano da Costa ${ }^{4}$; Gelson dos Santos Difante ${ }^{5}$

\section{Introdução}

Intensificar a criação de ovinos para a produção de carne no Brasil, necessita do controle dos efeitos ambientais e genéticos, que afetam o desenvolvimento dos animais e dependem da correta utilização dos manejos nutricionais, reprodutivos e sanitários.

O peso ao nascer determina a sobrevivência das crias e seus desempenhos subsequentes. Esse índice pode ser influenciado por fatores diretamente relacionados ao animal, como raça, idade, sexo da cria e tamanho dos pais, e por outros fatores como nutrição, sanidade e número de crias por parto. O ganho de peso médio diário, índice de importância para avaliação do desempenho animal, permite acompanhar o desempenho ponderal das crias, principalmente nos sistemas para produção de carne.

Diante do exposto, objetivou-se avaliar a influência do uso de suplementos em pasto diferido para matrizes e do tipo de parto sobre o desempenho dos cordeiros.

\section{Fundamentação Teórica}

A nutrição inadequada da ovelha, particularmente no estágio final da gestação, pode comprometer o desenvolvimento de alguns órgãos do feto que altera a fisiologia do animal e resulta em modificações no crescimento pré e pós-natal do cordeiro (GERASEEV et al., 2006).

\footnotetext{
${ }^{1}$ Doutoranda do Programa de Pós-graduação em Ciência Animal, UFMS, nat_rfc@hotmail.com

${ }^{2}$ Graduanda em Zootecnia, UFRN, adallat@yahoo.com.br

${ }^{3}$ Graduando em Agronomia, UFRN, roldao.agro@hotmail.com

${ }^{4}$ Graduanda em Agronomia, UFRN, beatrizcosta.0303@hotmail.com

${ }^{5}$ Professor do Programa de Pós-graduação em Produção Animal, UFRN, gdifante@hotmail.com
} 
Portanto, acompanhar desenvolvimento dos cordeiros a partir do peso vivo é uma prática que auxilia e possibilita o sucesso na produção de cordeiros. Pesar os animais nos períodos de 0 a 10 dias de vida, pode indicar a condição nutricional da matriz durante a gestação; de 10 a 30 dias, servirá para avaliar a habilidade materna da ovelha; e de 31 a 70 dias, demonstrará o potencial genético do animal em termos de conversão alimentar (PEREIRA E GRACINDO, 2006).

Nesse ponto de vista, Mexia et al. (2004) também destacaram o ganho de peso dos cordeiros como importante parâmetro do desempenho produtivo. De acordo com os autores, além de sofrer influência da nutrição materna, a velocidade de crescimento pode estar sob efeito do sexo do animal e do tipo de parto (simples ou gemelar).

\section{Metodologia}

O experimento foi conduzido na área do Grupo de Estudos em Forragicultura (GEFOR), na Universidade Federal do Rio Grande do Norte - UFRN, em Macaíba, RN. O período experimental foi de 30 de dezembro de 2015 a 19 de junho de 2016. O pasto (5,1 ha) de Brachiaria brizantha cv. Marandu foi vedado em meados de julho de 2015 e utilizado a partir de outubro do mesmo ano até junho de 2016. O método de pastejo empregado foi o de lotação contínua com taxa de lotação variável e ciclos de amostragem do pasto a cada 28 dias.

Os tratamentos constituíram-se de pasto diferido de capim-marandu submetido ao pastejo por matrizes ovinas suplementadas com mistura múltipla, $0,4 \%$ e $0,8 \%$ do PV de suplementação concentrada. A mistura múltipla foi composta de cloreto de sódio (20\%), ureia (10\%), milho moído (40\%) e farelo de soja (30\%), oferecida à vontade, e o concentrado das matrizes composto de milho moído $(80,5 \%)$, farelo de soja $(14,6 \%)$, cloreto de sódio $(1,2 \%)$ e ureia $(3,7 \%)$. Foram utilizadas 55 matrizes ovinas, sem padrão racial definido, com média de 120 dias de gestação. Foram gerados 61 cordeiros.

As crias foram mantidas no pasto maternidade de Panicum maximum cv. Massai com acesso livre a suplementação concentrada calculada para atender as exigências de cordeiros em fase de crescimento com ganhos de até 200 g/dia (66\% milho moído; 29,5\% farelo de soja; 3\% cloreto de sódio; e 1,5\% óleo de soja). O desaleitamento e desmame ocorreu aos 90 dias de idade de cada cria.

As crias foram pesadas após o nascimento e sempre a cada sete dias, até atingir 90 dias de idade. Cada cria foi avaliada de forma individual para o peso ao nascer, o ganho médio diário 
(GMD, g/animal.dia), calculado pela diferença de peso dos animais entre as pesagens dividida pelo número de dias entre cada pesagem, e o ganho de peso total (GT, kg/animal), obtido pela somatória de todos os ganhos de peso até o dia do desmame da cria.

O delineamento experimental utilizado foi inteiramente ao acaso, três tratamentos e número variável de repetições (cordeiros). As médias referentes ao efeito isolado do sexo e do tipo de parto foram comparadas pelo teste de Fisher e o efeito dos suplementos comparados pelo teste de Tukey, ambos a 5\% de significância.

\section{Resultados e Discussões}

O PV dos cordeiros ao nascimento, aos 30, 60 e 90 dias foi influenciado $(\mathrm{P}<0,05)$ pelo suplemento alimentar das matrizes (Tabela 1). As ovelhas suplementadas com mistura múltipla produziram cordeiros mais leves do nascimento ao desmame $(\mathrm{P}<0,05)$. As ovelhas suplementadas com concentrado em nível de $0,4 \%$ do PV produziram os cordeiros com o maior peso ao nascer. O PV dos cordeiros aos 30, 60 e 90 dias foi superior para os cordeiros filhos das ovelhas suplementadas com concentrado, independentemente do nível de suplementação.

Tabela 1. Peso vivo (PV) de cordeiros do nascimento ao desmame (90 dias) oriundos de partos do tipo gemelar e simples de matrizes suplementadas com mistura múltipla (M.M.), 0,4\% e $0,8 \%$ do PV, mantidas em pasto diferido de capim-marandu.

\begin{tabular}{|c|c|c|c|c|}
\hline & \multicolumn{4}{|c|}{ PV (kg/animal) } \\
\hline & Nascimento & 30 dias & 60 dias & 90 dias \\
\hline & \multicolumn{4}{|c|}{ Suplementação } \\
\hline M.M. & $3,56^{\mathrm{b}^{*}}$ & $7,24^{b}$ & $11,13^{b}$ & $14,68^{b}$ \\
\hline $0,4 \%$ & $3,97^{\mathrm{a}}$ & $8,82^{\mathrm{a}}$ & $13,94^{\mathrm{a}}$ & $18,42^{\mathrm{a}}$ \\
\hline \multirow[t]{2}{*}{$0,8 \%$} & $3,78^{\mathrm{ab}}$ & $8,77^{\mathrm{a}}$ & $14,13^{\mathrm{a}}$ & $19,04^{\mathrm{a}}$ \\
\hline & \multicolumn{4}{|c|}{ Sexo } \\
\hline Fêmea & $3,81^{\mathrm{a}}$ & $7,97^{\mathrm{a}}$ & $12,57^{\mathrm{a}}$ & $16,40^{b}$ \\
\hline \multirow[t]{2}{*}{ Macho } & $3,75^{\mathrm{a}}$ & $8,66^{\mathrm{a}}$ & $13,72^{\mathrm{a}}$ & $18,58^{\mathrm{a}}$ \\
\hline & \multicolumn{4}{|c|}{ Tipo do parto } \\
\hline Gemelar & $3,24^{\mathrm{b}}$ & $6,54^{\mathrm{b}}$ & $10,64^{b}$ & $14,63^{\mathrm{b}}$ \\
\hline Simples & $3,90^{\mathrm{a}}$ & $8,69^{\mathrm{a}}$ & $13,67^{\mathrm{a}}$ & $18,10^{\mathrm{a}}$ \\
\hline
\end{tabular}

*Valores seguidos por letras distintas na coluna diferem entre si $(\mathrm{P}<0,05)$ para efeito dos suplementos pelo teste de Tukey e para efeito isolado do sexo e do tipo de parto pelo teste de Fisher.

O peso ao nascimento, aos 30 e 60 dias não foram influenciados pelo sexo ( $\mathrm{P}>0,05)$. O sexo influenciou $(\mathrm{P}<0,05)$ o peso dos cordeiros apenas aos 90 dias de idade, machos apresentaram peso $11,73 \%$ superior em relação às fêmeas (Tabela 1). 
O tipo de parto influenciou $(\mathrm{P}<0,05)$ o peso vivo dos cordeiros (Tabela 1$)$, do nascimento ao desmame. Os animais nascidos de partos simples apresentaram os maiores pesos, em comparação aos partos gemelares. A principal razão para que os cordeiros gêmeos se apresentarem mais leves no período pré-desmame é a competição intrauterina pelos nutrientes e, após o nascimento, pelo leite materno (MOHAMMADI et al., 2010).

Houve efeito $(\mathrm{P}<0,05)$ da suplementação alimentar da ovelha no GMD dos cordeiros com 60 e 90 dias de idade, sendo os valores do GMD maiores para aqueles cujas mães foram suplementadas com concentrado (Tabela 2). A suplementação da matriz influenciou $(P<0,05)$ o GT dos cordeiros. Os maiores ganhos foram observados para os filhos das ovelhas suplementadas com concentrado, independentemente do nível utilizado (Tabela 2).

Tabela 2. Ganho de peso médio diário (kg/animal.dia) e ganho de peso total (kg/animal) de cordeiros machos (M) e fêmeas (F) do $30^{\circ}$ dia de idade ao desmame oriundos de partos do tipo gemelar e simples de matrizes suplementadas com mistura múltipla (M.M.) e suplementação concentrada ao nível de $0,4 \%$ e $0,8 \%$ do PV, mantidas em pasto diferido de capim-marandu.

\begin{tabular}{ccccc}
\hline & \multicolumn{3}{c}{ GMD (kg/animal.dia) } & \multirow{2}{*}{ GT (kg/animal) } \\
\cline { 2 - 4 } & 30 dias & 60 dias & 90 dias & \\
\hline M.M. & $0,142^{\mathrm{a}^{*}}$ & $0,104^{\mathrm{b}}$ & $0,126^{\mathrm{b}}$ & $11,16^{\mathrm{b}}$ \\
$0,4 \%$ & $0,172^{\mathrm{a}}$ & $0,151^{\mathrm{a}}$ & $0,172^{\mathrm{a}}$ & $14,91^{\mathrm{a}}$ \\
$0,8 \%$ & $0,153^{\mathrm{a}}$ & $0,176^{\mathrm{a}}$ & $15,25^{\mathrm{a}}$ \\
\hline \multicolumn{5}{c}{ Sexo } \\
\hline Fêmea & $0,155^{\mathrm{a}}$ & $0,127^{\mathrm{a}}$ & $12,62^{\mathrm{b}}$ \\
Macho & $0,175^{\mathrm{a}}$ & $0,148^{\mathrm{a}}$ & $0,137^{\mathrm{b}}$ & $15,16^{\mathrm{a}}$ \\
\hline & $0,181^{\mathrm{a}}$ & \\
\hline Gemelar & $0,134^{\mathrm{b}}$ & $0,104^{\mathrm{b}}$ & $11,38^{\mathrm{b}}$ \\
Simples & $0,172^{\mathrm{a}}$ & $0,145^{\mathrm{a}}$ & $0,143^{\mathrm{a}}$ & $14,41^{\mathrm{a}}$ \\
\hline
\end{tabular}

"Valores seguidos por letras distintas na coluna diferem entre si $(\mathrm{P}<0,05)$ para efeito dos suplementos pelo teste de Tukey e para efeito isolado do sexo e do tipo de parto pelo teste de Fisher.

Houve efeito do sexo $(\mathrm{P}<0,05)$ para o GMD na idade de desmame e para o GT (Tabela 2). Os machos se mostraram mais responsivos que fêmeas, porém esse efeito só fora percebido no desmame, pois aos 90 dias de idade ocorre influência dos hormônios sexuais, devido ao início da puberdade, a testosterona possibilita maiores ganhos de peso para os machos. Cordeiros machos são maiores e mais pesados que as fêmeas, essa diferença ocorre principalmente devido ao dimorfismo sexual e a influência hormonal (PACHECO e QUIRINO, 2008).

O tipo de parto influenciou ( $\mathrm{P}<0,05)$ o GMD, aos 30 e 60 dias de idade, e o GT (Tabela 2). 
Animais nascidos em parto gemelar foram mais leves aos 30 e 60 dias de idade, mas não houve diferenças entre o tipo de parto à desmama, isso pode indicar que a nutrição da matriz promoveu recuperação da condição de ganho de peso dos cordeiros. Portanto, se a nutrição da matriz for adequada, cordeiros gêmeos podem recuperar o peso até a desmama. Como o GT é uma consequência do GMD, o GT de crias gêmeas foi menor que o GT de crias oriunda de parto simples, pois a diferença ocorrida aos 30 e 60 dias de idade foi superior a recuperação do peso dessas crias gêmeas até atingir 90 dias de idade.

\section{Conclusões}

Cordeiros cujas mães recebem suplementação concentrada em nível de $0,4 \%$ do peso vivo apresentam melhor desenvolvimento e crescimento, além de maior viabilidade para o sistema de produção.

\section{Referências}

GERASEEV, L. C.; PEREZ, J. R. O.; CARVAlHO, P. A.; OLIVEIRA, R. P.; QUINTÃO, F. A.; LIMA, A. L. Efeitos das restrições pré e pós-natal sobre o crescimento e o desempenho de cordeiros Santa Inês do nascimento ao desmame. Revista Brasileira de Zootecnia, Viçosa, v. 35, n. 1, p.245251, fev. 2006.

MEXIA, A. A.; MACEDO, F. D.; ALCALDE, C. R.; SAKAGUTI, E. S.; MARTINS, E. N.; ZUNDT, M.; YAMAMOTO, S. M.; MACEDO, R. M. G. Desempenhos reprodutivo e produtivo de ovelhas Santa Inês suplementadas em diferentes fases da gestação. Revista Brasileira de Zootecnia, Viçosa, v. 33, n. 3, p. 658-667, 2004.

MOHAMMADI, K.; NASSIRI, M. T. B.; FAYAZI, J.; ROSHANFEKR, H. Investigation of environmental factors influence on pre-weaning growth traits in Zandi lambs. Journal of Animal and Veterinary Advances, Pakistan, v. 9, n. 6, p. 1011-1014, 2010.

PACHECO, A.; QUIRINO, C.R. Estudo das características de crescimento em ovinos. Pubvet, v.2, n.29, p.1982-1263, 2008.

PEREIRA, G. F.; GRACINDO, Â. P. A. C. Escrituração zootécnica. In: LIMA, Guilherme Ferreira da Costa et al. Criação familiar de caprinos e ovinos no Rio Grande do Norte. Natal: Emater-rn, Emparn, Embrapa Caprinos, 2006. Cap. 11. p. 257-277. 